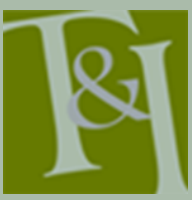

The International Journal for Translation \& Interpreting Research trans-int.org

\title{
Equal access to community interpreting in Flanders: a matter of self-reflective decision making?
}

Britt Roels

Flemish Agency for Civic Integration, Brussels

britt.roels@kruispuntmi.be

Marie Seghers

Centre for Diversity and Learning, Linguistics Department, Ghent University

marie.seghers@ugent.be

\section{Bert De Bisschop}

LANG+, Linguistics Department, Ghent University

bert.de.bisschop@ehb.be

\section{Piet Van Avermaet}

Centre for Diversity and Learning, Linguistics Department, Ghent University piet.vanavermaet@ugent.be

\section{Mieke Van Herreweghe}

LANG+, Linguistics Department, Ghent University

mieke.vanherreweghe@ugent.be

Stef Slembrouck

LANG+, Linguistics Department, Ghent University

stef.slembrouck@ugent.be

DOI: 10.12807/ti.107203.2015.a11

\begin{abstract}
The central issue tackled by this article revolves around decision-making by public service institutions in respect of the uses and perceived effects of community interpreting and translation in Flanders (Belgium) and/or other resources of language support (such as the use of a lingua franca, soliciting the help of a multilingual coworker, etc.). The aim of the study was to obtain a clear understanding of processes and participant frameworks of decision-making with regard to language support within these institutions. Consequently, a qualitative survey was set up focusing on three selected geographic regions and, within these regions, on four domains of public service (health, education, public administration and employment assistance). Respondents were both institutional end users and immigrants. The results reveal a lack of national and local organizational policy and explicit procedures in the allocation of language support resources. This lack contributes to inequality in foreign language users' access to the services of public institutions. It is recommended that a self-reflective framework be introduced for regulating access to a more systematic use of community interpreting alongside other instruments or strategies for bridging language barriers. Such a framework should be tailored to the needs of the institution's clients and to domainspecific and local needs of the institution. It should also include the relative availability of other adequate instruments for bridging language barriers.
\end{abstract}

Keywords: Flanders, community interpreting, decision-making, language bridging strategies, multilingualism

\section{Introduction}

Worldwide in recent decades, successive waves of migration have had an impact on communication in institutional encounters of service provision. Whereas such encounters used to be mostly monolingual, there has been a selective but nevertheless expanding transformation into multilingual 
encounters of service provision. Over the past 20 years north-to-south migration, e.g. migration from the United States to Brazil, has remained stable, and migration between countries of the south or between countries of the north has increased by less than one-third. However, south-to-north migration, e.g. from African countries to Europe, appears to have doubled in the same period of time (IOM, 2013, p. 56). Community interpreting (CI) plays a central role in enabling access to services provided by institutions in the host country alongside other strategies of language support (e.g. the use of a lingua franca).

With increasing migrant populations requiring language support services, the role of the community interpreter has become a focal area of research in interpreting studies. Topics that have received attention include client satisfaction (e.g. Carrasoquilo et al., 1999), mainly in health care the quality of interpreting practices (e.g. Kale et al., 2010), as well as the impact of interpretation on the interaction between the primary participants. ${ }^{1}$ By contrast, more policy-oriented studies have dealt with professional ethics and have contributed to political debates about the allocation of interpreting resources by governments and local authorities (e.g. Felsö et al., 2007). Such policy-oriented studies are a form of sociolinguistic research focusing on language policy and planning in migratory settings and the language resources used in the provision of multilingual services. Far less literature has focused on the nature of decisionmaking processes within institutions which regulate clients' access to interpreting services. This includes the strategies regulating the ways in which clients can request community interpreting rather than other (linguistic) resources such as the use of (formal or informal) cultural mediators, a lingua franca, pictograms, etc. Exceptions include Garrett (2009) who has published on the situation in Australia, though with an exclusive focus on health practitioners. These decision-making processes within institutions are the focus of our paper. We have concentrated on practices in Flanders, the Dutchspeaking region in the north of Belgium, an area with autonomy in language support policies.

Successive waves of immigration over the past 50 years have resulted in increased multilingualism in Flanders. Organized labour migration occurred in the early 1960s (Turkish, Maghreb, and before that Italian). It was followed by waves of political and economic refugees from the 1990s onwards. This most recent influx includes both east to west and south to north migration within the EU as well as (mainly) francophone post-colonial migration. Vanduynslager et al. (2013, p. 80) report for 2012 a total of 1,114,792 residents of foreign ancestry in Flanders (counted on the basis of first nationality and nationality of the parents). This amounts to $17.5 \%$ of the population.

\section{Community Interpreting in Flanders}

Flanders has a population of about 6 million. The official language is Dutch (the Belgian variety of Dutch is commonly referred to as Flemish). Community interpreting is not regulated at the federal Belgian level, but rather at the level of the language-specific regions. Thus, in Flanders, the provision of language services falls under the jurisdiction of the Flemish Ministry of Integration. Community interpreting covers interpreting in the public sphere, with the exception of legal contexts (police, the courts and the asylum procedure). Community interpreting covers both face-to-face interpreting and telephone interpreting (SERV/COC, 2007).

\footnotetext{
${ }^{1}$ Impact has been understood in professional/occupational terms (e.g. Bischoff et al. 2003) or in terms of the interactional dynamics (e.g. Jacobs et al., 2004; Karliner et al., 2011; Krystallidou, 2013).
} 
In the 1980s and 1990s, due to the rise in multilingualism and a growing awareness of the need to ensure equal access to social services for all, a number of community interpreting (CI) agencies surfaced in several Flemish cities and provinces (COC, 2007). They played a pioneering role. The Flemish Integration Decree of 1998 included CI as an element of civil integration policy. In 2009 this decree was altered to provide clarity on how CI was to be provided and organized in Flanders (Roels, 2013; Vermeiren et al., 2009). It identified nine CI agencies (eight local and one centralized). ${ }^{2}$ Moreover, the Central Support Cell for Social Interpreting ${ }^{3}$ was established as a unit of the Flemish Centre for Migration-Integration to provide a centralized support service for these CI agencies and to ensure the quality of community interpreting provided. In addition, the Flemish Centre for Migration-Integration (Kruispunt MigratieIntegratie) became the sole Flemish organization accredited by the European Social Fund to function as a test centre for community interpreters. Certification of community interpreters is now accomplished by means of a certification examination, based on a standardized professional competency profile. CI agencies are not permitted to commission uncertified community interpreters to any assignments if certified interpreters are available. However, the decision on whether or not to enlist the support of a community interpreter in an institutional setting rests entirely with the professional or institutional end user.

The Flemish Ministry of Integration attributes two functions to community interpreting: (i) to enhance access to language services for those in need of them and to guarantee the quality of these services in public social welfare organizations, and (ii) to further the integration of immigrants. However, the legislative framework does not detail how decisions to enlist the services of a community interpreter are to be made, except to state that the decision is taken by the institutional end user. Foreign-language speaking clients of organizations may request a community interpreter through the institutional agent providing the service, but it remains a discretionary decision of the institution whether or not an interpreter is present. No reference is made to the need of the client for a community interpreter or to any explicit procedure for how the institution is to arrive at a decision.

\section{A detailed survey of uses and effects}

The qualitative survey reported on in this paper was conducted from May 2012 to June 2013. It focused on the uses and effects of community interpreting and translation in the Flemish context. The survey was commissioned by the Ministry of Integration (European Integration Fund) and co-funded by the European Social Fund (http://www.esf-agentschap.be/). ${ }^{4}$ The research project comprised two stages: an exploratory phase and a validation phase in which the key insights were consolidated. Each stage involved a number of steps and a mix of qualitative research instruments (orally conducted questionnaires, indepth interviews and focus groups). In this article we will not focus on figures, as the samples are too small to make statistically significant generalizations. Instead, we will concentrate on the quality of the respondents' experiences, as justified by the project's qualitative research methodology which was oriented to understanding processes and participant frameworks of decision-making.

\footnotetext{
${ }^{2}$ On January $1^{\text {st }} 2015$ six of these nine CI agencies became part of the new Flemish Agency of Civic Integration. This reform is a consequence of the 2013 Flemish Integration Decree.

3 The Central Support Cell for Social Interpreting (COC) now forms part of the recently-established Flemish Agency of Civic Integration.

${ }^{4}$ The researchers were B. Roels, M. Seghers and B. De Bisschop. The principal investigators were S. Slembrouck, P. Van Avermaet and M. Van Herreweghe.
}

Translation \& Interpreting Vol 7 No 3 (2015) 
The first step of the exploratory phase consisted of an initial series of semistructured interviews with the coordinators and quality assurance workers of all nine CI agencies. In addition, we interviewed seven certified community interpreters and translators. On the basis of these interviews and an in-depth analysis of the statistics of use (see Roels et al., 2013 for more details), four institutional domains were selected for focused attention: public administration, employment assistance, health care and education. This selection was informed by three key considerations: (i) the statistics of use showed considerable differences in the frequency of CI use; (ii) organizations in these institutional domains appeared to make use of both professional (certified) community interpreters and informal ad-hoc interpreters; (iii) the function of $\mathrm{CI}$ in education and employment assistance appeared to be more directly linked to long-term goals of integration, whereas the corresponding use in public administration and health care seemed to emphasize facilitating access to services. To sample a representative spread of views across the Flemish region, three geographical areas were selected for detailed attention: the city of Ghent (an urban context), the provinces of West Flanders (a mixed urban-rural context) and Flemish Brabant (an urban-suburban context). This choice also reflected attention to specific (historical) dynamics of immigration. ${ }^{5}$

In the second and third steps of the exploratory phase, 60 oral interview questionnaires (30 institutional end users, 30 immigrants) focused on a series of questions relating to the use, the decision-making process and the perceived functional efficiency of CI against the background of alternative provisions of language support, including its impact on longer-term goals of integration. All selected respondents had a minimum of one-time experience with communication through a community interpreter or translator. All interviews were conducted either in Dutch or in the interviewee's preferred language by means of a community interpreter. The analysis of these interviews led to the development of a series of hypotheses, which were "piloted" in a supplementary series of in-depth interviews with nine end users and eight institutional clients, selected from within the two original groups.

In the validation phase of the research project, the focus was on how the field in its broadest sense would respond to the hypotheses. Vignettes (Brauer et al., 2009; Taylor, 2006), ${ }^{6}$ developed on the basis of the nine hypotheses (see below), were used to structure two series of in-depth interviews with newly selected respondents who had not participated in the exploratory phase: 15 institutional end users and 15 client immigrants. Again, these interviews were conducted either in Dutch or in the interviewee's preferred language by means of a community interpreter. In addition, four focus group sessions with end users were organized - one for each of the four institutional domains. In the following sections, we will discuss the key insights that were obtained on the basis of the hypotheses which pertain directly to the central theme of on-site processes of institutional decision-making on the use of CI.

\footnotetext{
${ }^{5}$ The city of Ghent is a major city in Flanders and has a rich history of organized labour immigration as well as new forms of immigration. The city also played a pioneering role in the provision of community interpreting. The province of West Flanders is mainly a rural area with some major city centres, with more recent patterns of immigration. The use of $\mathrm{CI}$ in this area is more recent. Flemish Brabant is a region of the urban and sub-urban type close to the capital Brussels. This has resulted in a considerable influx of immigrants, while the region is also reflective of a more polarized language environment (a history of publicly expressed resentment against the provision of services in other languages, notably French).

${ }^{6}$ Vignettes are hypothetical case scenarios that are presented to respondents who are asked to reflect on a familiar type of scenario. The use of vignettes is a strategy to elicit respondents' attitudes, judgements, beliefs, knowledge, opinions or decisions. The vignettes in our research were developed on the basis of the information gathered during the exploratory phase and supplemented by practical knowledge.
}

Translation \& Interpreting Vol 7 No 3 (2015) 


\section{Hypothesis 1: arbitrary use of community interpreting}

The survey results overwhelmingly indicate that $\mathrm{CI}$ is relied upon in a fairly arbitrary fashion. Large differences in frequency of use were noted between institutional domains, between organizations of the same institutional domain, between professionals of the same organizational unit, and even at the level of the individual professional.

During the interviews end users were asked how frequently the organization requested the services of a community interpreter. Their replies provided clear indications of arbitrary use of CI. No discernible patterns in frequency of use were evident. On the contrary, a lack of consistency was often expressed. Within the same domain, some organizations made use of CI twice a week, while another organization reported once a year. A further example of the arbitrary pattern of use was provided by two public service organizations in the same region. While they both provided the same services to clients with very similar profiles, one of them made use of CI once a month, whereas the other drew on CI services only once a year. These irregular patterns are confirmed by the statistics of use that were gathered during the exploratory phase.

The large variation in the use of CI will in some respects be due to differences in institutional domain, region or even the number of clients being served. However, large discrepancies quite independent of these factors became obvious, and these were confirmed by the interviews with the immigrant clients. Respondents provided ample accounts of different forms of language support being provided quite interchangeably. The excerpt quoted below provides an example of four different forms being relied upon within the same organization, possibly even by the same individual professional, i.e. a certified community interpreter, some basic Dutch, French as a lingua franca and an ad hoc interpreter. In this excerpt and in following excerpts $\mathrm{R}$ refers to researcher and I to interviewee:

\section{Excerpt (1)}

- $\quad$ R: Have you had an interpreter often here in the hospital?

- I: Yes, she did once at the doctor's, doctor's..., and I did it through the internet.

- $\quad R$ : Ah, an interpreter through the internet. And did you like that? Could you see the interpreter on the screen?

- I: Yes I saw him.

- $\quad$ R: Ah, sort of like Skype, yes. And how often do you come to the hospital?

- I: Normally three times here. ${ }^{7}$

- $\quad R$ : Three times, ok. And is there always an interpreter present when you're here?

- I: No.

- $\quad R$ : Then how do you communicate with hospital staff?

- I: I speak a little Flemish and I always speak French too.

- R:Yes.

- I: And sometimes I come here with a woman, a friend, and she can help sometimes.

(Moroccan woman, 35; our translation)

When probed specifically about the arbitrary use of CI, institutional end users often acknowledged the lack of a coherent framework and a lack of clear or explicit guidelines for assessing the client's needs and deciding on the use of an interpreter.

\footnotetext{
${ }^{7}=3$ times per week.
} 


\section{Excerpt (2)}

There are no real rules about when you can use an interpreter. You have to sort of intuitively decide whether or not it's necessary.

(Employment agency guidance counsellor, Flemish Brabant; our translation)

\section{Excerpt (3)}

I do think that at times we, I'm not going to say, 'leave patients to their own devices', but we do try to manage everything in Dutch, but afterwards we can't really be sure whether the patient has understood everything the doctor has said. I think that's something we can still work on in hospitals.

(Focus group, health care; our translation)

We observed both a lack of standard procedure for the use of CI and the absence of a policy within the organization for the provision of language support. Both contribute to arbitrary use. When encountering a foreignlanguage-speaking client, organizations or their professionals follow a very individual, often intuitive, path when choosing instruments or strategies for bridging language barriers. Consequently, consistency in decision-making becomes unlikely.

Organizations that try to uphold consistent practices in the provision of language support with a concomitant use of CI often report practical problems in accomplishing this. End users refer to the scale of the organization, the availability of $\mathrm{CI}$, the nature and the context of the services provided and budgetary issues as possible obstacles in the implementation of a uniform practice. During the course of this study we noticed that consistency in practice is more likely to succeed in smaller-scale organizations (e.g. schools, neighbourhood health clinics). They achieve this for instance by centralizing all requests for interpreters and putting one particular employee in charge of hiring interpreters. They can also rely on (government) allocated means for CI. They all emphasize the importance of a clear vision and support from the higher echelons in their institution.

The arbitrary use of CI ultimately translates into unequal treatment of non-native Dutch- speaking clients. There is uncertainty about the type of language support that will be provided at any one time and clients are therefore not assured of effective communication, however dire or important the situation addressed by the institutional encounter may be. An important further question therefore is whether the quality of provided services would improve if immigrants were to have direct, unmediated access to CI. This question was taken up as an additional question when testing the hypothesis.

\subsection{Direct access for clients?}

Although hypothetical, direct access to CI, in the sense that the community interpreter would be enlisted by the client, would offer some obvious advantages. Non-native speakers of Dutch would have the guarantee of effective communication and end users would not necessarily always have to deal with the complex task of assessing needs and arranging an interpreter. However, both groups saw mainly disadvantages and impracticalities in such a system.

The interviewed immigrant clients did not express a real need for direct access to CI. They implicitly requested a more consistent use of CI, but did not appear to be convinced that direct access would guarantee a more consistent use. The interviewed end users also voiced a number of objections to such a system:

- If the decision on whether or not to use CI were made solely by the client, the end user partly loses control over his/her work situation. 
- The system may complicate the task for the interpreter, as the client cannot procure the information or documents the interpreter may need to prepare for their assignment.

According to the end users, direct access would not necessarily result in less arbitrary use of CI either. They cited the following reasons:

- It may be difficult for some non-native Dutch-speaking clients to find their way to this type of service. They may be reluctant to contact an agency or possibly not even be aware of its existence.

- Some clients' sense of pride and desire for self-reliance may impact negatively. Clients may turn down the aid of an interpreter in situations when it is advisable to have one.

In a number of organizations non-native Dutch-speaking clients are provided the opportunity to indicate beforehand whether or not they desire the assistance of an interpreter. The end users of these organizations confirmed the objections stated earlier and acknowledged that such a system has its flaws, especially because some non-native Dutch speakers tend to overestimate their proficiency in the dominant language.

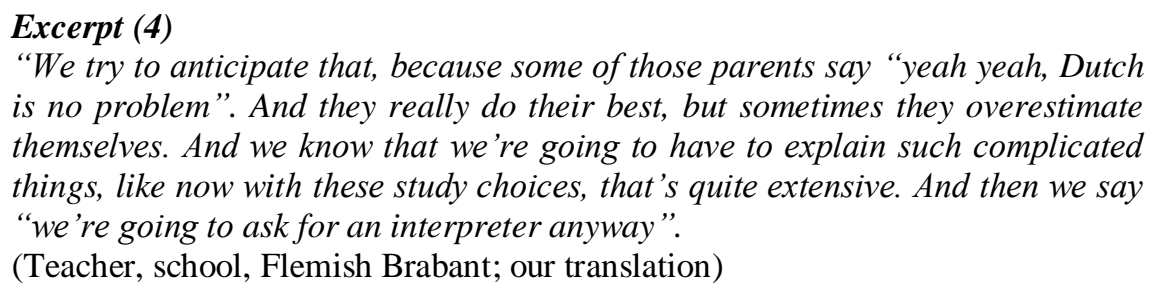

Given the potential flaws of this hypothetical system, it seems unlikely that direct access to CI for clients who are not native speakers of Dutch would lead to less arbitrary use and, by extension, a more optimal reliance on the available resources. This leads us to conclude that any system where the use of CI is decided by one party only will be more susceptible to the effects of arbitrary use. Similar conclusions were made by Norström et al. (2011) in their research on interpreters in Sweden, where the decision to enlist a community interpreter also rests with the institutional end users. It thus seems advisable to consult both parties always and to make the use of CI a shared responsibility.

\section{Hypothesis 2: professional autonomy versus the client's coping strategies}

In the exploratory phase a scale of relative "closeness/distance of resource" was identified in the reasoning of both institutional end users and immigrant clients, which may inform decision-making (Collins \& Slembrouck, 2006). In a "pecking order" of resources the use of Dutch would come out on top; next is the use of a lingua franca; after that, ad hoc interpretation by a person within the organization or by someone brought along by the client; only then comes the option of enlisting an externally-recruited professional interpreter. This form of scalar reasoning informed the hypothesis that a professional has a vested interest in maintaining their professional autonomy and is therefore reluctant to depend on third parties, such as a community interpreter, to perform their tasks. For a professional, the preferred practice would be to communicate directly with clients, one-on-one, without the help of or dependence on third parties. The immigrant clients showed a similar attitude when expressing a preference or even insistence on managing things on their own and avoiding reliance on externally recruited third parties to communicate with professionals. 


\subsection{The professional's perspective}

Hypothesis 2 was partly confirmed during the validation phase. Professionals clearly acknowledged the importance of the safeguarding of their professional autonomy. However, respondents who often made use of interpreters did emphasize how the use of a community interpreter guarantees adequate and efficient service. Less experienced end users tended to see a contrast between the values of professional autonomy and the use of CI.

Throughout the interviews we distinguished two sets of determining factors which interact directly with a stated preference for direct communication. These are (i) practical and financial motivations and (ii) motivations which stem from a certain ideology or relate to an organization's mission or vision. Familiarity and (positive) experiences with CI play a decisive role in the decision-making process. Less experienced end users tend to stress the (mostly presumed) complexity of the CI application procedure and do not really seem to know what to expect from a community interpreter. The more often a professional uses $\mathrm{CI}$, the fewer barriers s/he appears to experience. The vision of an organization and/or the individual ideology of its professionals may also underscore the preference for direct communication in the dominant local language. Some end users believe that speaking Dutch with their clients is the only correct way of communication. This belief originates in the idea that speaking languages other than Dutch is either an obstacle to the effective integration of the non-native Dutch speaker client or a violation of Belgian language legislation. ${ }^{8}$

\section{Excerpt (5)}

- $\quad R$ : Is it important for you to first communicate directly?

- I:Yes

- $\quad R$ : Do you find it difficult (to communicate) when an interpreter is present?

- I: Actually, no, because in the end all that is said is interpreted perfectly and then I'm sure she's got it, especially when it concerns difficult conversations, for day to day conversations I don't find it necessary, but with difficult situations I really think it is necessary.

(Cultural mediator, school, Ghent; our translation)

The principle of direct communication, preferably in Dutch, is also reinforced or weakened by the type of service offered. In the case of frequent contacts with clients over an extended period of time, there are more opportunities to make well-considered choices for specific instruments of communication compared to one-off encounters, because the professional knows the client better. In contrast, institutional domains with a mission to promote the civil integration of immigrants (e.g. employment assistance and social welfare) tend to emphasize the use of Dutch more than for instance health institutions, and they tend to do so from the perspective that their insistence on Dutch furthers the integration of their clients.

Our interviews with some experienced end users also revealed the existence of a form of informal step-by-step procedure in the decision-making process. The nature of the conversation, the possibility or impossibility to communicate in a lingua franca, and the availability of other resources of communication determined whether or not a more experienced end user would hold fast to the principle of direct communication.

\footnotetext{
${ }^{8}$ Belgian language legislation stems from the Language Act on Administrative Affairs (1966) which regulates the use of language in public affairs, within administrative offices as well as in contact with citizens: http://www.efnil.org/documents/languagelegislation-version-2007/belgium/belgium.
}

Translation \& Interpreting Vol 7 No 3 (2015) 


\subsection{The immigrant client's perspective}

In the exploratory phase the interviewed clients also showed a clear preference for direct communication as a demonstration of self-reliance. This hypothesis was confirmed during the validation phase. Nevertheless, many respondents mentioned misunderstandings which had been the result of insufficiencies in communication and came with negative consequences. These findings are corroborated by research with immigrants from ex-Yugoslavia in Swedish health care institutions (Habziabdic et al., 2009). The presence of interpreters was found to increase the immigrants' feeling of dependency and experienced as an impediment. Nevertheless, the immigrants considered professional interpreters as highly necessary to communicate effectively with care providers and to find their way in the health care system. They also showed a clear preference for professional interpreters, comparable to the immigrants in our research.

A similar process of scaling among the clients was thus detected. It ranges (at the "closeness" end of the scale) from the preference for communication in Dutch via communication in a lingua franca or with the help of relatives or friends, to - if available - assistance by a multilingual service provider and finally, if offered by the professional, the use of CI.

\section{Excerpt (6)}

- I: I would not do it often (make use of a community interpreter), since my Dutch is good enough to communicate myself. If I can explain by myself it's better than to wait for an interpreter. But it depends on the difficulty of the conversation.

- $\quad$ R: For what kind of conversations would you ask for an interpreter?

- $\quad$ I: Ehm, talking about illness is hard, that situation would be better with an interpreter.

(Chechen man, age 42, Ghent; our translation)

In cases where the minority language is more commonly spoken in Flanders, the chances are higher for clients to encounter a professional who speaks their language. This is for instance the case for Turkish immigrants in Ghent since Ghent has a long history of immigration from Turkey. Some second and third generation descendants of Turkish immigrants, having grown up bilingually in Dutch and Turkish, are now professionals who can assist clients in both languages (conversely, native doctors in one neighbourhood health clinic in the city have learned Turkish to a high level of proficiency). In our study we came across quite a few examples of clients and professionals who referred positively to the occurrence of multilingual professionals, especially in health care. Yet, our research equally testifies the use of multilingual employees who lack the necessary language and professional competencies as also being quite common. In one of the interviewed neighbourhood health centres the cleaning lady would sometimes be invited to step in and interpret. This information confirms the arbitrary use of language mediation strategies. Immigrants never really know what kind of services they can expect to encounter and what type of language support will be provided. The absence of a well-considered communication strategy can greatly diminish the quality of the services provided for immigrants, who often already live in precarious circumstances.

\section{Hypothesis 3: the added value of community interpreting}

Our third hypothesis maintains that the use of CI offers added value, especially when it is compared to informal ad hoc interpretation provided by relatives, friends or neighbours of the immigrant client. This was confirmed during the validation phase. 
According to all the interviewed end users and clients, professional community interpreters offer a considerable added value compared to ad hoc interpreters. The perceived added value of CI lies in the professional ethics of the community interpreters, which ensures neutrality, objectivity and confidentiality, their language proficiency and the extent of their interpretation (exhaustive, not selective). The use of ad hoc interpreters is reported to lead to distorted information, misinterpretations or omissions. It can create awkward situations for all parties taking part in the conversation. Nevertheless, the use of ad hoc interpreters remains a common and frequent practice. Many professionals still require immigrant clients to bring their own ad hoc interpreter to bridge the language barrier. This puts significant pressure on the immigrant. A friend or relative may not be readily available.

\section{Excerpt (7)}

If I need to go somewhere, I want to go with someone, but that person has to work, he cannot say: I'm not going to work, I'll go with you. So what happens, if I have to wait, I have to wait to arrange things ... I feel like an intruder if I have to go to neighbours or others, he only has one day off from work and just wants to rest or has to do errands or whatever.

(Turkish woman, age 42, Ghent; our translation)

\section{Excerpt (8)}

An interpreter is someone you don't know and you can tell him everything. Whereas with a friend or family member, when it concerns private matters you cannot always tell those things in their presence. For instance when you go to the trade union and you have a problem and you want to tell it there and your friends don't know about it you are forced to explain your situation in front of them.

(Turkish woman, age 30, Ghent; our translation)

\section{Excerpt (10)}

A professional interpreter speaks good Dutch, so if I could choose between someone from my family or a professional interpreter, I would certainly prefer the latter.

(Chechen woman, age 40, Ghent; our translation)

Research with Serbo-Croatian and Russian refugees in Irish health care institutions shows similar findings (MacFarlane et al., 2009). These refugees experienced the responsibility of finding an ad hoc interpreter as a huge burden. The use of ad hoc interpreters also increased worries about wrong diagnosis and treatment. The institutional end users similarly confirm the added value of professional CI.

\section{Excerpt (11)}

The problem is that those amongst the family members who are the most eligible (to interpret) are the best integrated, and generally they are the ones working, for whom it's more difficult (to come to the hospital to interpret). Those who can come and interpret, are the ones who are not fully socially, not 100\% integrated or reliable as an interpreter. Who can interpret is also relevant.

(Head nurse, hospital, West Flanders; our translation)

CI is generally perceived as an instrument to help and as a favour to the immigrant. However, our research shows that it is an instrument benefitting the professional as well. CI is an important instrument to enhance the quality of services and may result in more job satisfaction, an important observation to be made in the current context of super-diversity and increasing multilingualism. 


\section{Excerpt (12)}

Our aid workers are less frustrated when they feel they can provide good quality care due to the use of interpreters instead of having to manage by themselves and being left with the feeling that they are very frustrating visits.

(Focus group, health care; our translation)

\subsection{Do multilingual doctors, teachers, etc. provide an alternative?}

Our research focused on CI but organizations generally use a wide range of resources to bridge language barriers. Some examples are:

- The professional may speak the client's language;

- The interactants may resort to a lingua franca;

- The end user may turn to others with the same or other occupational backgrounds in the organization who are proficient in the client's language;

- The end user may rely on intercultural mediators, etc.

We also touched upon these resources other than CI during the interviews. We cannot elaborate on these in this paper, but we would like to draw attention to two remarks with respect to multilingual professionals:

Firstly, the term "multilingual professional" seems to be an umbrella term for a very diverse group of people with substantial variation in linguistic competences, job specific competences and professional and/or occupational backgrounds. For some, interpreting is part of their job qualification, for others it is a task sometimes allocated to them even though the quality of their competence in the language required has never been assessed. The contrast between such multilingual professionals as the Flemish bilingual nurse versus the Polish cleaning lady can serve as an example here. Some end users take these considerations into account when deciding whether or not to make use of a multilingual colleague, but unfortunately not all do so. Whereas the professionally qualified end user who is adequately proficient in the client's language provides an indisputable alternative to the community interpreter, the use of multilingual employees needs to be considered carefully and made subject to some form of assessment.

Secondly, the use of multilingual professionals is widespread and still growing. CI and multilingual professionals are not mutually exclusive choices but complement and reinforce each other. In a super-diverse society not all immigrant languages are commonly known and used; it may be impossible to find a multilingual professional for some of these languages. The sole and unreflected use of multilingual professionals could thus exclude people who speak these less common languages from high-quality communication and service provision. Consequently, the promotion of a range of resources for bridging language barriers will always be necessary. Consequently, a framework for an institutional communication policy with attention to CI alongside other resources such as multilingual professionals can be helpful in guiding professionals in their daily decision-making. Such a framework would contribute to the promotion of the consistent, efficient and effective use of multilingual bridging practices. In such a decision-making process the topic and scope of the interaction play an important role.

\section{Hypothesis 4: topic and scope of interaction as key factors in decision- making}

When asked "When do you request the services of a community interpreter?" a large portion of the interviewed end users replied as follows: "When I know beforehand that it is going to be a difficult consultation." In making this 
comment, they referred to linguistic challenges as well as challenges which pertain to the topic and purpose of the encounter with the client. The difficulties manifest themselves in three ways:

- The delicacy or sensitivity of what is being discussed;

- The complexity of the information that needs to be exchanged;

- The severity of the consequences the encounter may have for the client.

\subsection{Delicacy or sensitivity of the issue(s)}

By taking into account the delicacy of the topic, end users avoid embarrassing situations such as the one referred to in the quote below, where an ad hoc interpreter might be quite inappropriate for the scope and nature of the encounter.

\section{Excerpt (13)}

For example when I had an appointment at the gynaecologist, I didn't want my son to act as an interpreter, because ehm... I come from a Muslim country and for us it's very odd that boys are ehm... aware of such issues to be interpreted in such a context.

(Chechen woman, age 40, Ghent; our translation)

End users also report that the need for effective communication is crucial when sensitive topics are being discussed, as their clients may become quite emotional. In these cases they often ensure effective communication beforehand by booking a community interpreter. Ad hoc interpreters are often family members, who may feel emotionally involved in the matter and may therefore have difficulties in maintaining distance and focus on the task of interpreting. The superior language proficiency and guaranteed objectivity of the community interpreter make them the preferred resource to bridge a language barrier.

\section{Excerpt (14)}

When it's a difficult consultation, and this is going to be a difficult consultation because there are problems in the situation, then you're actually asking that ehm family member to act as an objective interpreter, which is very difficult. We never do that, we try to avoid that as much as we can.

(School welfare coordinator, school, Flemish Brabant; our translation)

\subsection{Complexity of the information and its consequences}

Clients need to be well-informed and the end users need accurate information to perform their professional duties. However admirable the efforts of end users and clients may be, their foreign language proficiency sometimes proves insufficient to communicate the complex information that is required in a language which is not their first language. Complexity of message and nuanced understanding are often vital, for instance, in the design of a care plan, an application for a scholarship etc. In such situations, the practical and other advantages of direct communication are superseded by the complex requirements of accurate and nuanced formulation, making the use of a community interpreter the preferred communicative strategy.

\section{Excerpt (15)}

In cases like that it goes very smoothly. There doesn't have to be an interpreter there because I just had something in my hand and I just gave it to her. She gave me the ID card, I said thank you, goodbye and I left. But when it's complicated things like the scholarship. Yeah, to ehm...explain what that is and how it works, then I do need an interpreter.

(Turkish woman, 42, Ghent) 
End users also tend to use a community interpreter for exchanges that do not necessarily have linguistically complex content, but where the situational demands may have severe or far-reaching consequences for the client (e.g. the communication of bad news).

\subsection{Restrictive decision-making?}

The main constant in all these cases is the end users' expressed need for effective communication. They generally associate this need with interactions that are sensitive, complex, important or decisive. However, a number of end users added that a decision-making process channelled in this direction would be too restrictive. They felt that the need for effective communication should not be solely reserved for such "weighty" and "difficult" exchanges and considered it equally important to communicate effectively in "less demanding" situations. Another criticism was that it would be very difficult to categorize interactions in this way: how and where does one draw the line between complex/delicate and not so complex/delicate communication? Interactions may also take an unexpected turn.

It emerged as a visible pattern in this study that end users determined the need for a community interpreter on the basis of the topic of the interaction and the institutional task at hand. It may be considered as a rational, though not exclusive, basis for using CI.

\section{Should the provision of community interpreting for immigrants be limited in time?}

In Flanders the use of $\mathrm{CI}$ is widely seen as a temporary measure, only to be used for a limited time to bridge the period in which the immigrant newcomer is expected to have mastered Dutch. The assumption that almost anyone, regardless of their background and personal situation, can become self-reliant in Dutch is generally unquestioned. People often expect long-term integration to go together with full mastery of the locally dominant language. An additional research question was therefore tagged on to the fourth hypothesis. Do professionals believe that access to CI should be restricted in time? And, what would be the effects of such a measure on the accessibility and quality of public social welfare institutions?

The institutional end users generally rejected the idea of limiting CI in time, depending on the length of time an immigrant had been resident in Flanders. We present their arguments below, taking them into consideration and placing them against examples of the use of CI as a strategy to achieve accessible and high-quality services and advance the integration of immigrants. Firstly, the prevailing argument is that restricting CI in time does not take into account the differences among individuals with regard to (foreign) language learning. The end users gave many examples of people who, due to age, limited schooling, sickness, precarious living conditions, aptitude, etc., are unable to obtain a language proficiency which is sufficient to communicate effectively with professionals from various institutional domains. These findings are corroborated by international research on language provision (e.g. Krum \& Plutzar 2010).

\section{Excerpt (16)}

It would be a very difficult rule to apply. Also, it really depends on the person in question. How he is taught the language. Since we have a lot of low-skilled parents, it's in any case not easy to learn a language.

(Cultural mediator, school, Ghent; our translation) 
Secondly, the nature of the interaction, a subject already touched upon above, plays a significant role in the professionals' rejection of limiting the period of accessibility to CI. Most interviewees confirmed that the nature of an interaction is a determining factor in the decision to use CI. Professionals decide to hire a community interpreter when high proficiency in Dutch is required for complex or emotional exchanges. These are often exchanges which involve the use of specific terminology and which touch upon institutional decision-making with far-reaching consequences for the clients. Many first generation immigrants never attain a sound command of the Dutch language. Research has shown that successful language transition can easily take up to three generations (Van Avermaet, 2008).

\section{Excerpt (17)}

Like I said in the beginning, if you talk about complex situations or delicate matters, it's not taken for granted to be able to do this in another language in the course of two years. You don't have to be unrealistic about it.

(Focus group, education; our translation)

Thirdly, restricting the provision of $\mathrm{CI}$ in time could have an adverse effect on access to services and the quality of their provision. Those who are likely to suffer the most from time restrictions are the most vulnerable group of immigrants (low educational level, little exposure to education). ${ }^{9}$ By discontinuing CI, the participation of immigrants in social institutions may be hampered. The time restriction may thus be counter-productive to the long-term goals of successful participation in the host society. The specific language background of the immigrant may also become a mechanism of exclusion in its own right. While the idea of time restriction is probably motivated by the assumption that, after a period of time, all communication should take place in Dutch, in reality this may mean that the foreign language continues to be accessed via either multilingual professionals or ad hoc interpreters. At the same time, the use of multilingual professionals is more widespread in urban regions, so that immigrants living in non-urban areas and/or speaking a less commonly available language, may be under more pressure to conduct all their affairs at all times in Dutch. Hence a Turkish speaker in a rural area or a Dari speaker in an urban area, for instance, may be disadvantaged.

Finally, certain restrictions already apply in some institutional domains and adding more restrictions would not make any sense. CI services offered by employment agencies or the welfare department of local authorities are at present already conditional in nature. Aid and/or service provision is tied to target-oriented commitments on the part of the client who may be asked to produce "proof" confirming that they have made serious efforts to find a job or that they have enrolled in an educational programme. Professionals reported seeing little benefit in adding further restrictions to the conditions for the provision of access to CI. At the same time, they indicated that they should be the ones determining under what circumstances $\mathrm{CI}$ is needed, regardless of the client's length of stay in the country.

\section{Discussion and conclusion}

Our focus in this article has been on reported experiences of language mediation (CI, in particular) and institutional/organizational decision-making in this area

\footnotetext{
${ }^{9}$ Danish research on the introduction of a client fee for CI after seven years' residence in the country (Harpelund et al., 2010) indicates how this primarily affects immigrants outside the labour force, with modest income, and often with poor health. The research concludes that the measure reinforces ethnic and social inequalities in access to health care.
} 
across social domains. The various stages in the research project, which fed into each other, have enabled us to arrive at an in-depth understanding.

The study relates to a key aspect of national language policy, i.e., the provision of language support for institutional clients whose first language is not Dutch. Two years ago, the United Nations' World Migration Report (IOM, 2013) was quite open in equating development goals in a context of migration with the well-being of people. Such an approach, it is argued, is consistent with "recent new orientations in thinking about development that are not limited to economically based notions such as productivity, wealth or income". Therefore, few arguments can be presented in favour of a more restricted provision of CI than is currently provided in Flanders today.

Service providers and institutional agencies continue to face a superdiverse clientele characterized by a multiplicity of multilingual repertoires and often with highly idiosyncratic trajectories of language learning and use. If anything, the numbers of non-Dutch speaking clients are increasing. Serviceproviding organizations and agencies appear to draw on a range of language bridging strategies in dealing with this super-diverse, multilingual reality, noting pros and contras, while also reporting frustration about on-the-ground experiences. Political voices expressing concern about current "excessive use" of CI contrast starkly with the widely noted preference for direct communication detailed above: CI often is not the first choice. At the same time, our research has shown that more experienced end users are more inclined to make active use of CI and that their decision-making relating to the provision of language support is often better informed and carefully considered. However, such experienced end users remain a minority. They are no more than "atomistic" instances of good practice by single individuals within an organization and are not necessarily the result of coordinated effort or explicit policy.

The absence of an explicit instrument or protocol of decision-making remains in all likelihood the most important insight our survey provides. If anything, it points to the need for a more stimulating rather than a more restrictive policy of situated reflection and active awareness about choice and strategy as well as balanced decision-making. The development of a framework for institutional communication policy is one factor that could usefully assist organizations delivering public services in developing a clear and consistent approach to CI. Such an approach should be tailored to the needs of the institution's clients and to the domain-specific and local needs of the institution. Ideally this would be done with explicit attention to important local conditions which may be client-, case- or organization-specific. It should also include the relative availability of other adequate instruments for bridging language barriers. Undoubtedly, no one-size fits all. More than language planning, today's multilingual and multicultural context calls for language management (Jernudd \& Nuestupny, 1987; see also Jernudd \& Nekvapil, 2012, pp. 33ff.) which is process-oriented, involves cycles of analysis, intervention and assessment and attends both to macro dimensions of national and institutional policy and to micro dimensions of local agency.

In short, what is required is the development of a self-reflective framework for organizational communication policies in which attention can be paid to a more systematic use of CI alongside other instruments or strategies for bridging language barriers. While the conditions for the development of such a framework should be stipulated at national level, it should be clear that the success of such an initiative is likely to depend on its "in-house" adaptability to domain-specific priorities and the specific functioning of local organizational units (client populations, linguistic profile of the end users, typicality of particular task-oriented encounters, etc.). The bottom-up development of such an instrument is then perhaps very much about offering sets of relevant questions, keeping a local record of decision-making, analysing aims and 
outcomes, and the like, which, each in its own right, may contribute to building a self-reflective tradition in the use of language bridging resources in a local organizational unit of service provision.

\section{References}

Bischoff, A., Bovier, P.A., Rrustemi, I., Gariazzo, F., Eytan, A., \& Loutan, L. (2003). Language barriers between nurses and asylum seekers: their impact on symptom reporting and referral. Social Science \& Medicine, 57(3), 503-512.

Brauer P.M., Hanning, R. M., Arocha, J. F., Royall, D., Goy, R., Grant, A., Dietrich, L., Martino, R., \& Horrocks, J. (2009). Creating case scenarios or vignettes using factorial study design methods. Journal of Advanced Nursing, 65 (9), 1937-1945.

Carrasquillo, O., Orav, J., Brennan, T.A., \& Burstin, H.R. (1999). The impact of language barriers on patient satisfaction in an emergency department. Journal of General Internal Medicine, 14(2), 82-87.

Centrale Ondersteuningscel voor Sociaal Tolken en Vertalen (COC). (2007). Sectoraal dossier sociaal tolken en vertalen. Brussels.

Collins, J., \& Slembrouck, S. (2006). "You don't know what they translate": Language contact, institutional procedure and literacy practice in neighborhood health clinics in Urban Flanders. Journal of Linguistic Anthropology, 16(2), 249-268.

Felsö, F., Baarsma, B., Gerritsen, M., \& Mulder, J. (2007). Tolken in het publieke domein. Over de vraag, aanbod en de bemiddeling van tolken. Amsterdam: Wetenschappelijk Onderzoek- en Documentatiecentrum.

Garrett, P. (2009). Interpreter Policy and Healthcare: Policy determinants and current issues. The International Journal for Translation \& Interpreting Research, 2(1), $32-43$.

Hadziabdic, E., Heikkilä, K., Albin, B., \& Hjelm, K. (2009). Migrants' perceptions of using interpreters in health care. International Nursing Review, 2009, 461-469.

Harpelund, L., Smith, S., \& Krasnik, A. (2012). Self-perceived need for interpreters among immigrants in Denmark. Scandinavian Journal of Public Health, 40, 457465.

International Organization for Migration (2013). World Migration Report. Geneva.

Jacobs, E.A., Shepard, D.S., Suaya, J.A., \& Stone, E. (2004). Overcoming language barriers in health care: costs and benefits of interpreter services. American Journal of Public Health, 94(5), 866-869.

Jernudd, B. H., \& Neustupny, J.V. (1987). Language planning for whom? In L. Laforge (Ed.), Proceedings of the International Colloquium on Language Planning, 6984. Québec: Les Presses de l’Université Laval.

Jernudd, B.H., \& Nekvapil, J. (2012). History of the field: a sketch. In: Spolsky, B., Cambridge Handbook of Language Policy (pp. 16-36). Cambridge: CUP.

Kale, E., \& Syed, H.R. (2010). Language barriers and the use of interpreters in the public health services. A questionnaire-based survey. Patient Education and Counseling, 81, 187-191.

Karliner, L.S., Hwang, E.S., Nickleach, D., \& Kaplan, C.P. (2011). Language barriers and patient-centered breast cancer care. Patient Education and Counseling, 84, 223-228.

Krystallidou, D. (2013). The Interpreter's Role in Medical Consultations as Perceived and as Interactionally Negotiated. A Study of a Flemish Hospital Setting, Using Interview Data and Video-recorded Interactions ( $\mathrm{PhD}$ dissertation, Ghent University).

Krumm, H.J., \& Plutzar, V. (2010). Tailoring Language Provision and Requirements to the Needs and Capacities of Adult Migrants. Council of Europe.

MacFarlane, A., Dzebisova, Z., Karapish, D., Kovacevic, B., \& Ogbebor, F. (2009). Arranging and negotiating the use of informal interpreters in general practice consultations: experiences of refugees and asylum seekers in the west of Ireland. Social Science \& Medicine, 69, 210-214.

Norström, E., Gustafsson, K., \& Fioretos, I. (2011). Interpreters in Sweden: A Tool for Equal Rights? Lund University.

Roels, B. (2013). Certification of Social Interpreters in Flanders, Belgium. Assessment and Politics. In D. Tsgari, \& R.Van Deemter (Eds.), Assessment Issues in Language Translation and Interpreting (pp. 179-197). Frankfurt: Peter Lang. 
Sociaal-Economische Raad van Vlaanderen (SERV), \& Centrale Ondersteuningscel voor Sociaal Tolken en Vertalen (COC). (2007). Beroepscompetentieprofiel Sociaal Tolk. Brussels: SERV.

Taylor, B.J. (2006). Factorial surveys: using vignettes to study professional judgement, British Journal of Social Work, 36, 1187-1207.

Van Avermaet, P. (2008). Taalverschuiving in de Italiaanse Gemeenschap in Eisden, Maasmechelen. (PhD dissertation, KULeuven).

Vanduynslager, L., Wets, J., Noppe, J., \& Doyen, G. (2013). Vlaamse Migratie- en Integratiemonitor 2013. Brussels: Agentschap voor Binnenlands Bestuur.

Vermeiren, H., Van Gucht, J., \& De Bontridder, L. (2009). Standards as critical success factors in assessment. Certifying social interpreters in Flanders, Belgium. In C.V. Angelelli \& H.E. Jacobson (Eds.), Testing and Assessment in Translation and Interpreting Studies (pp. 297-329). Philadelphia: John Benjamins Publishing Company. 